\title{
Application of environmentally friendly concrete demolition techniques in the repair of shipping locks
}

\author{
Vladimir Bazanov ${ }^{1, *}$ \\ ${ }^{1}$ Moscow State University of Civil Engineering, Yaroslavskoye sh., 26, 129337, Moscow, Russia
}

\begin{abstract}
The paper analyzes the traditional mechanic technique of concrete demolition and the promising hydro demolition techniques from viewpoint of waterworks operators. The mechanical concrete demolition technique using chisel hammers is immediately available for the use and relatively cheap, but it is associated with considerable labor cost, generation of dust and noise. Concrete hydro demolition technique using high-pressure water has much higher productivity and reduces repair completion time, does not damage reinforcement, and ensures good adhesion of new concrete to old concrete. Basic technical characteristics of hydro demolition equipment and its pricing are given. On the basis of the current situation with regard to the estimated regulation and financing of construction projects, including from budgetary funds, the author considered the possibility of using promising methods of removing exposed concrete of lock chamber walls. A comparison was made between the cost and the regulatory and actual labor intensity between the methods of mechanical and hydraulic destruction of concrete. It has been shown that application of the hydraulic demolition technique is constrained by financial capabilities and estimates regulatory requirements. For substantiation of using the concrete hydro demolition techniques, operators need to adjust the regulatory framework for federal assessments.
\end{abstract}

\section{Introduction}

Most waterworks facilities in Russia have been in operation for more than 60 years and those of the Moscow Canal - over 80 years. The long term and conditions of operation lead to deterioration of the concrete condition in shipping locks' chambers, especially in variable water level areas. Concrete destructions are being accumulated, sometimes exposing reinforcement. The necessity of maintaining safe functioning of shipping locks requires periodic overhauls of the exposed surface of chamber walls' concrete in order to bring the technical condition of shipping waterworks facilities (hereinafter, SWWF) to the level that is assessed as operable. The exposed concrete replacement works start with removal of the destroyed layer. Demolition of concrete facilities is usually accompanied with a lot of dust, loud noise, and impact loads. Pursuant to Code 349.1325800.2017 "Concrete and

*Corresponding author: bazanov_kim@mail.ru 
Reinforced Concrete Structures. Repair and Reinforcement Rules", the applied technique of repair and refurbishment works should provide for health and environmental protection measures and should be implemented in line with environmental, and sanitary and technical requirements, especially in urban development areas. Air dust content should not exceed the maximal permissible concentration (MPC) of contaminants in community air.

Repair regularity might vary between $10-15$ to $35-40$ years depending both on operation conditions and concrete work quality. It is necessary to take into account the specifics of performing repair and construction works: shipping locks can be repaired, as a rule, only during the internavigational period, approximately from mid or late November to March, i.e. in winter. The total completion period (the area of lock chamber walls being 10-12 thousand $\mathrm{m}^{2}$ and over) might take two to three internavigation periods, which necessitates stopping works prior to navigation opening and technologically re-starting the construction and assembly works when navigation closes. At present, the requirement for exposed concrete repair of lock chamber walls in the Moscow Canal facilities only exceeds 100 thousand $\mathrm{m}^{2}$. The depth of the surface layer replacement varies and depends on the old concrete condition. For instance, inв 1997-2007, on the eastern and western walls of Moscow Canal lock \#2, exposed concrete replacement was carried out using the 'column' technique. The surface concrete layer of the face side was replaced to the depth of 30 to 50 $\mathrm{cm}$ [1]. Ground-penetrating radar survey of lock \#13 chamber in Gorodetsky District Waterworks showed the depth of zones with compromised structure of exposed concrete reaching 2 to $60 \mathrm{~cm}$ and in some areas - down to $3.0 \mathrm{~m}$ from the wall surface, i.e. almost to the whole wall thickness [2].

Due to considerable scopes of repair works, it is most relevant to choose techniques to remove destroyed exposed concrete that would efficient both from the engineering and economic, and environmental friendliness points of view [3].

\section{Materials and Methods}

Considerable scopes of repair works make the choice of destroyed exposed concrete demolition technique most relevant from both engineering and economic and environmental points of view. The paper analyzes the traditional mechanic technique of concrete demolition and the promising hydro demolition techniques from viewpoint of waterworks operators. The mechanical concrete demolition technique using chisel hammers is immediately available for the use and relatively cheap, but it is associated with considerable labor cost, generation of dust and noise. Concrete hydro demolition technique using high-pressure water has much higher productivity and reduces repair completion time, does not damage reinforcement, and ensures good adhesion of new concrete to old concrete. Basic technical characteristics of hydro demolition equipment and its pricing are given.

\section{Results}

On the basis of the current situation with regard to the estimated regulation and financing of construction projects, including from budgetary funds, the author considered the possibility of using promising methods of removing exposed concrete of lock chamber walls. A comparison was made between the cost and the regulatory and actual labor intensity between the methods of mechanical and hydraulic destruction of concrete. It has been shown that application of the hydraulic demolition technique is constrained by financial capabilities and estimates regulatory requirements. For 
substantiation of using the concrete hydro demolition techniques, operators need to adjust the regulatory framework for federal assessments.

\section{Discussion}

The traditional way of removing exposed concrete is its demolition using hand hammer drills or pneumatic hammers, which is connected, first of all, with availability and relative cheapness of equipment used. It is rather difficult to use mechanisms (hydraulic hammers) due to work conditions (up to $18-22 \mathrm{~m}$ high vertical surfaces), and the necessity to minimize impact loads on concrete. To do the work, scaffolding is erected in a pumped out lock chamber to the whole wall height, and concrete is demolished in tiers [4, 5]. Around the installed scaffolding, to their total height, a transparent enclosure (pavilion) is erected. Using electric heaters, positive ambient temperature is maintained inside the pavilion to warm up frozen surfaces and metal structures, and to maintain the necessary temperature conditions during concreting jobs. From the scaffolding installed, old concrete is cut out, bore holes are drilled, and anchors are installed, concrete is laid. The main types of works performed during overhaul of lock chamber walls are:

- lock chamber pumping out;

- concrete demolition;

- reinforcement demolition;

- demolition of sealing splines in expansion joints;

- installation of reinforcement and laying concrete of walls;

- installation of expansion joint sealing splines.

Defective concrete is cut out from top to bottom. To remove weak concrete, chisel hammers with low impact energy are used. Concrete is cut out in two steps: at the first one, concrete is cut out using light or medium-weight chisel hammers; at the second one - using light electric hammer drills or hand tools to remove small spalls. The quality of cutout work is checked by knocking with a hammer. Later, the following works are carried out:

- clearing of the surface to be repaired;

- removal of reinforcement corrosion products by sand blasting;

- cleaning of the prepared surface from dust by blowing with air from a compressor;

- in raking concrete repair areas, anchors and reinforcing cages are installed according to detailed engineering drawings;

- installation of formwork;

- concrete surface rinsing with warm water until full saturation;

- concrete mix laying into the formwork.

However, this method has considerable drawbacks, too. Due to impact loads, microfissures develop in the remaining concrete layers, i.e. additional structural destructions deep in the wall occur, which affects the overhaul time. Pneumatic and hydraulic chisel hammers compromise structural reinforcement integrity. Adhesion of new concrete to old concrete decreases significantly [6], necessitating installation of additional anchorage. Besides, works are characterized by high labor intensity, are harmful for staff, and produce much noise and dust, which has to be taken into account when works are carried out in community areas.

It should be noted that this technique is included in the State Itemized Construction Estimates GESNr 69-16 "Demolition of Concrete and Reinforced Concrete Structures Using Chisel Hammers", which causes no difficulties related to the necessity of substantiating the cost of works in estimate documentation because almost all SWWF including locks are the federal property and their repairs are made at the expense of federal budget grants or funds of Russian Federation State Program "Transport System Development" (approved by the Government Decree No. 1596 dated 20 December 2017). 
Another, alternative, technique of concrete removal is hydraulic destruction or hydro demolition, which is selective removal of damaged concrete using high-pressure water. A water pump delivers a high volume of water at a pressure of $950-3000$ bars into an operating tool - a water jet propeller. A thin water jet from the propeller nozzle penetrates into pores and cracks in concrete creating internal pressure. When this pressure exceeds the tensile strength of concrete, concrete is destroyed and removed with the same jet. Concrete hydro demolition works are produced using a compressor station and hydro demolition robot (manual atomizers or frame fittings can also be applied). The system is equipped with a diesel engine, which makes the work self-sustained, or it can be connected to 3-phase electric mains.

According to manufacturers, the indicative range basic parameters of hydro demolition equipment is as follows:

- Water pressure: 950 - 3000 bars

- Water flow rate: 30 - 300 liters per minute

- Diesel engine (water pump) power: 120 - $750 \mathrm{~kW}$

- Water jet speed: 200 - $600 \mathrm{~m} / \mathrm{sec}$

- Hole diameter in the propeller nozzle: 2 - $4 \mathrm{~mm}$

- Concrete demolition depth: $0-0.5(1.0) \mathrm{m}$

- Demolition capacity: $0.5-1.5(2.5) \mathrm{m}^{3} / \mathrm{hr}$.

The equipment allows round-the-clock continuous operation. Concrete is removed from horizontal (including ceiling) and inclined surfaces, and from vertical surfaces to any height of a structure. Thanks to adjustability of water jet pressure (speed), it is possible to remove concrete, which strength is below a certain preset value, selectively.

The main consumables are fuel, water, and nozzles (atomizers). During repair of waterworks facilities, water is no problem; in most cases, no special treatment system is required. It is possible to recirculate water. Consumption of atomizers also depends, first of all, on water purity. Today, atomizers made from different materials are commercially available (stainless steel; alloys bearing high friction of particles; ceramics; сапфир).

Hydro demolition produces rough clean free-of-microfissures surface providing good adhesion of new concrete to old concrete. Reinforcement is not damaged and becomes fully cleared of residual corrosion and concrete. According to laboratory test results [10], adhesion for surfaces formed by the hydro demolition technique is twice higher than in case of mechanical processing. Of special note is the fact that hydraulic destruction of concrete has no adverse environmental impacts: no dust is generated, destroyed concrete (broken stones) can be re-used for construction works.

The hydro demolition technique has been successfully and widely used abroad since the 1990 s in the repair of reinforced concrete structures of bridges, dikes, tunnels, hydroelectrical power plants. The experience of repair of the hydro-electrical power plant on the Drava River (Slovenia) is of interest: there, concrete was removed to the depth of $840 \mathrm{~mm}$ ( $780 \mathrm{~mm}$ in two runs plus the third clean run of $60 \mathrm{~mm}$ ), the productive rate being about 1 $\mathrm{m}^{3} / \mathrm{hr}$. This technique is used in Russia, too. For example, in 2014-2015, overhaul of lock \#7 in Volga-Baltic Canal was carried out. To remove concrete, Aquaet Systems AB equipment was used. Thanks to high capacity (in some areas with weakened concrete it reached $5 \mathrm{~m}^{3}$ per hour) and preservation of the existent reinforcement cage, the total completion period of the repair works amounted to 2 internavigational periods instead of 3 , as had been provided for by the construction method statement.

Comparison of different concrete demolition techniques, their advantages and drawbacks, was undertaken by foreign and domestic authors [6]. In paper [6], for comparison, the experimental works carried out at the Uglich hydro-electric power plant in an area of $1 \mathrm{~m}^{2}$ were taken. However, in public media, there are insufficient actual data that would allow establishing the efficiency and applicability of techniques under comparison. 
Let us undertake an approximate comparison by the demolition speed and cost between two demolition techniques - mechanical (using chisel hammers) and hydraulic. For comparison, we will use State Itemized Construction Estimates (GESN) and Federal Unit Rates (FER), and input from vendors of hydro demolition equipment.

We will establish the costs for chisel hammer works according to GESN 46-04-003 and, correspondingly, FER 46-04-003 "Demolition of Concrete and Reinforced Concrete Structures in a Volume Exceeding $1 \mathrm{~m}^{3}$ Using Chisel Hammers". The scope of works in the said regulations take into account only demolition of reinforced concrete structures and cutting of reinforcement (the choice of estimates regulations arise from the minimal scope of works compared to GESNr 69-16 "Demolition of Concrete and Reinforced Concrete Structures Using Chisel Hammers", which scope of works include: work site preparation, set-up of chisel hammers, demolition of reinforced concrete structures, cutting of reinforcement, and waste removal). According to GESN 46-04-003, demolition of reinforced concrete structures for concrete of grade 200 costs $33.74 \mathrm{men} / \mathrm{hr}$. per $1 \mathrm{~m}^{3}$; the chisel hammer work itself costs $28.38 \mathrm{men} / \mathrm{hr}$. per $1 \mathrm{~m}^{3}$. According to FER 46-04-003, direct expenses amounts to 1800 rubles per $1 \mathrm{~m}^{3}$. Considering the predicted index of change in the cost of construction and assembly works for the 4th quarter of 2018, which is 8.09 for the Moscow Region, direct expenses will amount to 14,563 rubles.

Currently, there are no federal unit rates for hydro demolition works. Assuming the 'mean' stated productive rate equal to $1 \mathrm{~m}^{3}$ per hour, we will get a 25-30-fold gain in time approximately. The indicative cost of hydro demolition works based on commercial offers varies within 100 - 150 thousand rubles per $1 \mathrm{~m}^{3}$ depending on conditions, i.e. 6-10 times more expensive.

Thus, there being obvious advantages as regards assurance of surface quality for subsequent concrete works, considerable gain in terms of completion period, improved sanitary and environmental situation, application of hydro demolition is associated with a considerable increase in cost compared to the common technique of removing concrete by chisel hammers. Besides, hydro demolition equipment is manufactured by foreign manufacturers and is characterized by a quite high price. The price of hydro demolition frames begins from 16 million rubles and the price of power stations complete with a hydro demolition robot amounts to 45 million rubles and more depending on the scope of delivery. Such equipment is affordable only for organizations specializing in repair works and possessing a multi-year portfolio of orders or scopes of work sufficient for return on investment into equipment.

In addition to financial constraints hindering use of the hydraulic technique to demolish concrete, one more issue should be noted, which is related to estimates regulation. In accordance with the current laws, the estimate documentation for overhaul and refurbishment of highly hazardous and sophisticated facilities (such as hydro-engineering facilities of class one and two), which are funded at the expense of the federal budget, must pass verification of reliability of estimates in Federal Autonomous Institution "Glavexpertiza of Russia". In the development of estimate documentation for the said facilities, estimate rates included in the federal register should be used. The current absence of developed and approved federal estimate rates for hydro demolition works renders it rather difficult to substantiate use of this concrete demolition technique.

\section{Conclusions}

In a situation of limited funding of repair and refurbishment works at federal SWWF, the possibility of applying hydro demolition of concrete will largely depend on adoption of state estimate rates and reduction of the equipment price that can be achieved through development and manufacture of equipment domestically. 


\section{References}

1. S. Levachev, T. Fedorova, Proceedings of Moscow State University of Civil Engineering, Vestnik MGSU 8, 137-149 (2013)

2. A. Krasavin, D. Krasavin, A. Balashov, V. Molyavin, Hydrotekhnika. XXI Century 4, 66-69 (2015)

3. C. Anumba, A. Abdullah, T. Fesseha, Structural Survey 21(1), 36-48 (2003)

4. I. Tanikura, R. Shintani, A. Sainoki, S. Watanabe, Y. Obara, Construction and Building Materials 164, 193-205 (2018) https://doi.org/10.1016/j.conbuildmat.2017.12.220

5. V.M. Davidenko, G.B. Okhapkin, O.E. Bibina, B.E. Vedeneev, VNIIG Review 289, 52-58 (2018)

6. A.W. Momber, Elsevier Science 1, 263-269 (2005) https://doi.org/10.1016/B978185617460-2/50009-3 